\title{
Relación de la obra del pintor Antonio López con la fotografía. Métodos de un maestro rechazado como profesor
}

\author{
Relation of the work of the artist Antonio Lopez with the \\ photography. Methods of a teacher rejected as a professor
}

\author{
Lino CABEZAS-GELABERT \\ Departamento de Dibujo. Universitat de Barcelona. \\ linocabezas@ub.edu \\ JOAN C. OLIVER \\ Universitat de les Illes Balears \\ joancarlesoliver@gmail.com
}

Recibido: 22 de noviembre de 2013

Aprobado: 23 de febrero de 2014

\section{Resumen}

En 1966 el pintor Antonio López fue rechazado en la Escuela Superior de Bellas Artes de San Fernando para acceder a la cátedra de "Preparatorio de colorido", en donde presentó su Nevera de hielo. Después de cinco años de encargado de cátedra abandonó la institución. El artículo analiza las circunstancias de la prueba, en una década que supuso un cambio definitivo en su obra, hacia un realismo incómodo para un sistema que mantenía con dificultad la copia académica del modelo, una tradición difícilmente compatible con la abstracción que se imponía en la España de aquellos años. A la vez, las relaciones con la fotografía han condicionado las reflexiones teóricas del pintor y los métodos de trabajo analizados en estas páginas.

Palabras clave: Antonio López, fotografía, academia.

Cabezas-Gelabert, L., Oliver, J.C. (2015): Relación de la obra del pintor Antonio López con la fotografía. Métodos de un maestro rechazado como profesor. Arte, Individuo y Sociedad, 27(1) 25-43

\begin{abstract}
In 1966 the artist Antonio Lopez was rejected for the chair in "Preparatorio de colorido" (Preparatory Colouring) by the San Fernando School of Fine Arts where he himself presented his work Nevera de hielo (Ice Box). After 5 years as a "stand in" for this post he left the Institution. This article analyzes the circumstances and proof of a decade where there appears to be evidence of a definite change in his work, more toward Realism, uncomfortable in a system that maintained with difficulty the traditional academic model copy, and incompatible with, in those years was imposed by Spain. At the same time his relation with photography conditioned by the theoretical thoughts of the artist, and his work methods also are analyzed in this article.
\end{abstract}

Keywords: Antonio López, Photography, Academy. 
Sumario: 1. El joven profesor, 2. Concurso-oposición, 3. La construcción de un estilo, 4. La "visión" fotográfica, 5. ¿Copiar fotografías?, 6. Pintar del natural, 7. Elección de modelos con "misterio", 8. La maestría en la copia del natural, 9. Perspectiva geométrica y fotografía, 10. Conclusiones. Referencias.

\section{El joven profesor}

Muy pocos saben que la obra Nevera de hielo (Fig. 1a) pintada por Antonio López en 1966 fue una de las pruebas realizadas en un "concurso-oposición" al que se presentó para acceder a la cátedra de "Preparatorio de colorido" de la antigua Escuela Superior de Bellas Artes de San Fernando de Madrid (Desde 1964 hasta 1969 fue encargado de la càtedra de "Preparatorio de colorido" que en ese período se convocaría a concurso-oposición en dos ocasiones, la primera en una Orden de 11de marzo de 1966 publicada en el B. O. del E. del 7 de abril). No fue su único trabajo, la otra obra presentada en la misma convocatoria consistió en una "academia", un desnudo femenino pintado de un modelo del natural (Fig 1b). El resultado negativo, al no aprobar la oposición, dejó desconcertados a los que habían sido alumnos de "Antoñito" (Escribiremos "Antoñito" al hablar del pintor en torno a los años sesenta, y Antonio López en su madurez.) en aquel curso académico 1965-1966, definido por una experiencia excepcional para una promoción en donde muchos alcanzarían el reconocimiento por la calidad y personalidad de sus propias obras. La deuda de sus alumnos hacia aquella experiencia, además de ser evidente por la influencia en sus obras como pintores, se ha recordado en muchas ocasiones (En El Semanal $N^{o} 678$ de octubre de 2000, dedicado al pintor, se publica una crónica titulada "Así le ven sus ex alumnos", en donde los pintores José María Mezquita, Carmen Álvarez, Alfonso Galván y Florencio Galindo evocan su deuda con el maestro. También fueron alumnos de aquel curso, entre otros pintores conocidos, Pedro Cano, Cayetano Portellano y José M ${ }^{a}$ González Cuasante).

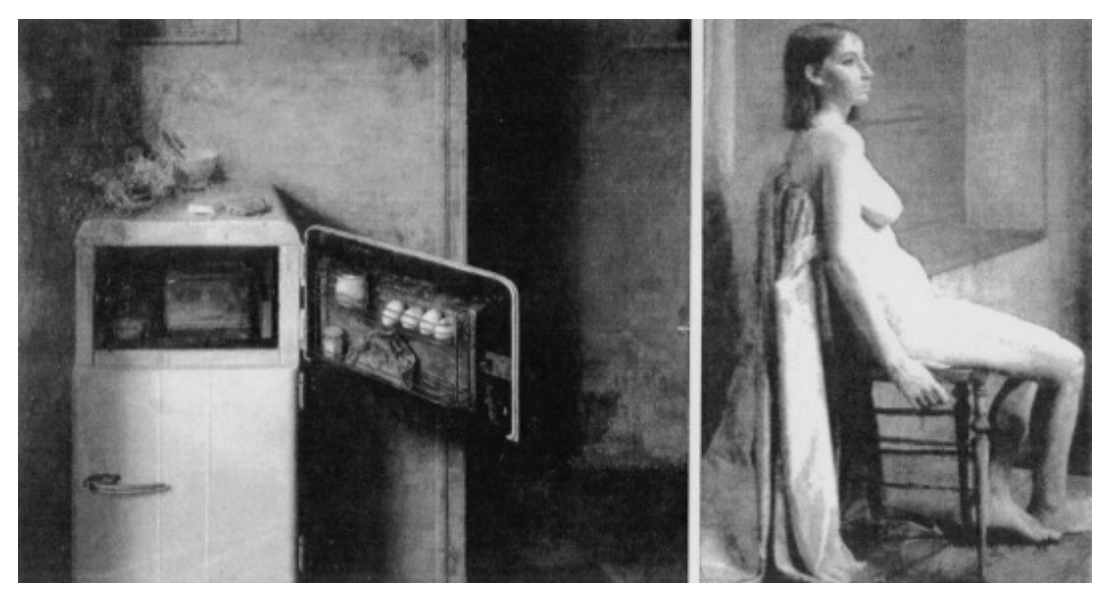

Figura 1 A. López. a) Nevera de hielo (1966). Col. particular.

b) Mujer sentada en una silla (1966). Col. Particular. 
Cuando comenzaba hace más de 47 años el curso, Antonio López aún no tenía 30 años, y el aspecto juvenil de entonces, su actitud tímida y cuerpo menudo pueden ayudar a comprender el apelativo Antoñito con el que era conocido por sus amigos; también sus alumnos se referían así al pintor y siguen refiriéndose los que forman parte de aquella generación a pesar del tiempo transcurrido.

En estas líneas se trata de reunir datos para ayudar a comprender una paradoja, ¿cómo pudo rechazarse como profesor de Bellas Artes a aquel Antoñito que fascinaba a los alumnos con su actuación en el aula, demostrando su personalidad al pintar la Nevera de hielo en las pruebas de la oposición? Sorprendentemente, años después se encumbraría al maestro Antonio López con innumerables premios, homenajeándolo, nombrándolo miembro de número de la Real Academia de Bellas Artes de San Fernando (1993) y adulándolo de forma casi obscena por las mismas instituciones que lo habían rechazado. No se trata tanto de especular sobre los criterios o el veredicto negativo del tribunal, sino de reconstruir una parte del contexto de aquellos acontecimientos y de su obra de entonces, aunque el testimonio vivo de los jueces ya no es posible (El Tribunal fue nombrado en una Orden de 26 de mayo de 1966, publicada en el B. O. del E. del 13 de junio.).

Debe recordarse que en esos años, la enseñanza de las Artes en España se desarrollaba en las Escuelas Superiores de Bellas Artes anteriores a su conversión en las actuales Facultades universitarias (Las Escuelas Superiores se transformaron en Facultades Universitarias durante el curso académico 1978-1979.). Los estudiantes de entonces eran "alumnos" y de los profesores se esperaba que fuesen maestros en su arte, para avalar con el ejemplo de su propia obra las instrucciones, y los preceptos, máximas y consejos que justificaban su labor como profesores.

Antoñito era encargado de cátedra en la primera asignatura de pintura, el "Preparatorio de colorido", a la espera del nombramiento definitivo de un catedrático titular. Ejercía interinamente su docencia en una de las aulas del último piso del edificio de la Real Academia de Bellas Artes de San Fernando, en el número 13 de la calle de Alcalá. Las clases se desarrollaban en las primeras horas de la mañana para aprovechar la luz natural. La ambigüedad del nombre de la asignatura, "Preparatorio de colorido", se resolvía con una tradición no escrita en donde se pintaban "naturalezas muertas" antes de hacerlo del "modelo vivo" del natural en los cursos posteriores. La Nevera de hielo, pintada por Antoñito para aspirar a la plaza de catedrático se inscribía en una pintura denominada genéricamente de bodegones.

\section{Concurso-oposición}

El concurso-oposición se convocó en el Boletín Oficial del Estado el 7 de abril de 1966 y la presentación ante el tribunal para el comienzo de las pruebas se fijó el día 5 de agosto tras su anuncio en el B. O. del E. del día 18 de julio. Acabadas las pruebas, el resultado final se publicaría en el mismo medio, en una Orden firmada por el ministro Lora Tamayo en la que, después del "Considerando que en la tramitación del concurso-oposición se han cumplido todos los requisitos legales, que la propuesta, en sentido de declarar desierta la cátedra de Madrid por mayoría absoluta de votos...", se aprobaba el expediente con "La declaración de no haber lugar a la provisión de la cátedra de Madrid". 
Al realizarse en Madrid las oposiciones para toda España, en las mismas fechas y para la misma asignatura de la Escuela Superior de Bellas Artes de San Jorge de Barcelona, proponía como "Catedrático numerario de "Preparatorio de Colorido" de dicha Escuela a don Armando Miravalls Bové" después de la consideración de "adjudicar la de Barcelona al señor Miravalls Bové por unanimidad" (B. O. del E. del 25 de enero de 1967).

La cátedra de Madrid, declarada desierta, se cubriría poco tiempo después tras otra convocatoria en donde 6 de los 23 admitidos también se habían inscrito en la anterior. Uno de ellos, el pintor Guillermo Vargas Ruiz, lograría ser propuesto para la plaza, "por mayoría absoluta de votos". Así, el 31 de julio de 1969 fue nombrado Catedrático numerario de la asignatura que había impartido "Antoñito" interinamente, un hito que marcará el comienzo de su destierro dorado de la academia antes de regresar aclamado bajo el mismo arco triunfal por donde fue expulsado.

Debe precisarse, no obstante, que no se juzgaba a los candidatos exclusivamente en la fase práctica de los ejercicios, entonces se podía decidir la adjudicación de la plaza en la fase de concurso, algo que se hacía explícito en la propia normativa: “ [en] caso de destacar notoriamente los méritos de alguno de los aspirantes, [el Tribunal podrá] proponerlo para el desempeño de la cátedra, sin necesidad de realizar ningún ejercicio de oposición". Aunque el currículum artístico de los candidatos no llegase al extremo de ser determinante en la fase de concurso, era importante para la resolución definitiva, y uno de los méritos del pintor Miravalls, admitido por unanimidad para la cátedra de Barcelona, era su ortodoxia académica.

\section{La construcción de un estilo}

Los cambios producidos en más de cuatro décadas, no son sólo los de la evolución del criterio público, condicionado por las profundas revoluciones sociales, tecnológicas y culturales, también son evidentes las transformaciones sustanciales en la obra de Antonio López. El mismo pintor ha reconocido que desde los primeros años sesenta "Estaba, pienso, en el umbral de lo que ya es mi lenguaje más o menos definitivo" (López, 2007: 60).
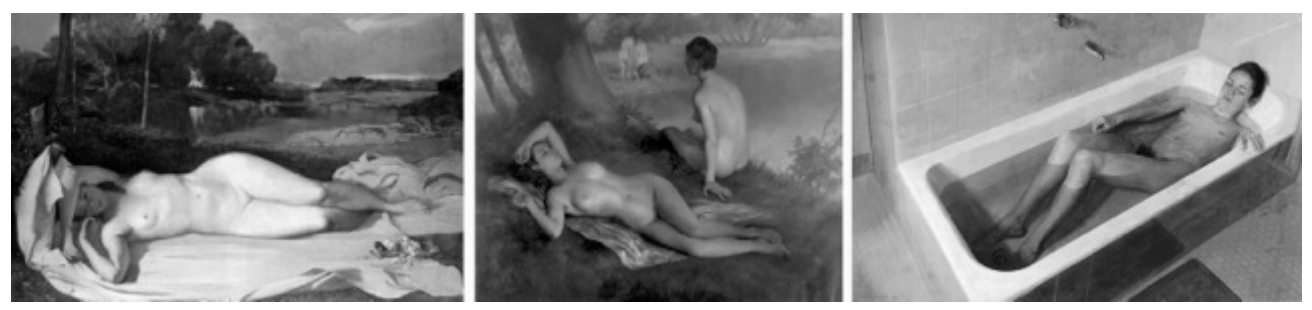

Figura 2. Desnudos pintados por: Miravalls Bové, Vargas Ruiz y Antonio López. 
Con la distancia de más de cuatro décadas estamos en condiciones de contrastar con más facilidad las diferencias entre la obra de los catedráticos nombrados para Barcelona y Madrid y la pintura de Antonio López. Para ello podemos comparar tres desnudos, ilustrativos de cada personalidad, aunque no son las obras realizadas en las pruebas (Fig. 2), y la que elegimos de Antoñito está pintada un año y medio después del concurso-oposición. Previamente advertimos que en la pintura de Antonio López de entonces así como en su método de enseñanza, era tanto o más importante "lo que decir" (su personalísimo mundo) que la manera "cómo debe decirse" (la forma de pintar) (Gómez, 1999: 519 ss.). En consecuencia, si nos preguntamos "cómo" están pintados los desnudos de los tres artistas, se puede convenir provisionalmente que están todos "bien pintados", para poder centrar la atención en las diferencias respecto a "qué" ha pintado cada uno. La deuda de la obra de Miravalls (1916-1978) hacia la pintura academicista, respetuosa con la pintura barroca o renacentista, al modo de las Venus de Tiziano, es evidente; a su vez, la de Vargas Ruiz (1910-1990) refleja su fidelidad hacia una tradición más reciente de la pintura "au plein air" en donde son frecuentes las escenas de baños con cuerpos desnudos en espacios abiertos, próximas a las popularizadas por Renoir. Ciertamente cada una de estas pinturas se remite o reconstruye un universo particular diferente.

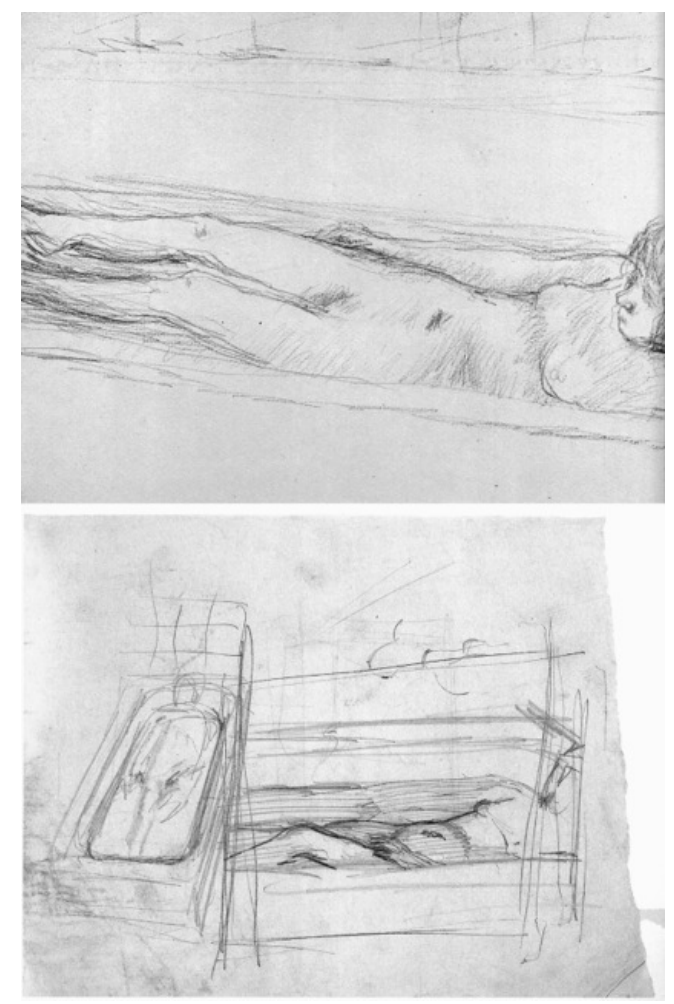

Figura 3. Dibujos de desnudo en la bañera por Bonnard (1925) y A. López (1967). 
Con el cuadro Mujer en la bañera sucederá lo mismo que en la Nevera de hielo: ser en los ambientes académicos de su época el más transgresor. Aunque es muy cierto que el motivo de una mujer en la bañera se había pintado y fotografiado antes innumerables veces, y de forma magistral por Pierre Bonnard (1867-1947) (Fig.3), de cuya obra se había realizado en 1967 una exposición en Madrid, inaugurada en la Galería Juana Mordó el 8 de febrero con la presentación de Fernando Chueca (El anuncio del acto de presentación de la exposición se publicó en el $A B C$ el 8 de febrero de1967, p. 61.). En la primera exposición colectiva de la galería, al abrirse en 1964 también había participado Antonio López con una obra, y pintaría su Mujer en la bañera un año más tarde de la exposición de Bonnard. Con ello no se puede, en absoluto, afirmar que exista una relación directa entre la obra del pintor francés con la de Antonio López, ya que las diferencias entre ambos artistas son muy grandes, aunque señalarlas nos permite precisar mejor la personalidad del pintor manchego.

\section{La "visión" fotográfica}

Mientras que el modo de pintar de Bonnard es deudor y continuador de la pintura impresionista, la obra de Antonio López de los años sesenta está relacionada directamente con el "modo de ver" de la fotografía. Y como diferencia principal de las relaciones con la fotografía se puede señalar que la actitud del pintor Bonnard, también fotógrafo, consistía en utilizar y subordinar las fotografías que él mismo realizaba, tal como había hecho Degas (1834-1917), al servicio del "modo de ver" de la pintura impresionista, mientras que Antonio López evocaba la "visión" fotográfica en sus pinturas aunque no fuese de forma totalmente consciente.

Esta idea se puede ratificar con el testimonio del propio pintor cuando explicaba las circunstancias del retrato de sus abuelos ya fallecidos, Sinforoso y Josefa (1955), realizado a partir de una fotografía (Fig. 4): "Era una fotografía familiar en blanco y negro muy antigua y muy deslucida por tantos años [...] los hice, claro, sin tenerlos delante: los hice de la fotografía. Me inventé el color y trabajé por primera vez fuera de lo que el natural me podía dar, que era lo que yo tenía por costumbre. Después he trabajado con mucha frecuencia de la fotografía" (López, 2007: 49, 50). 

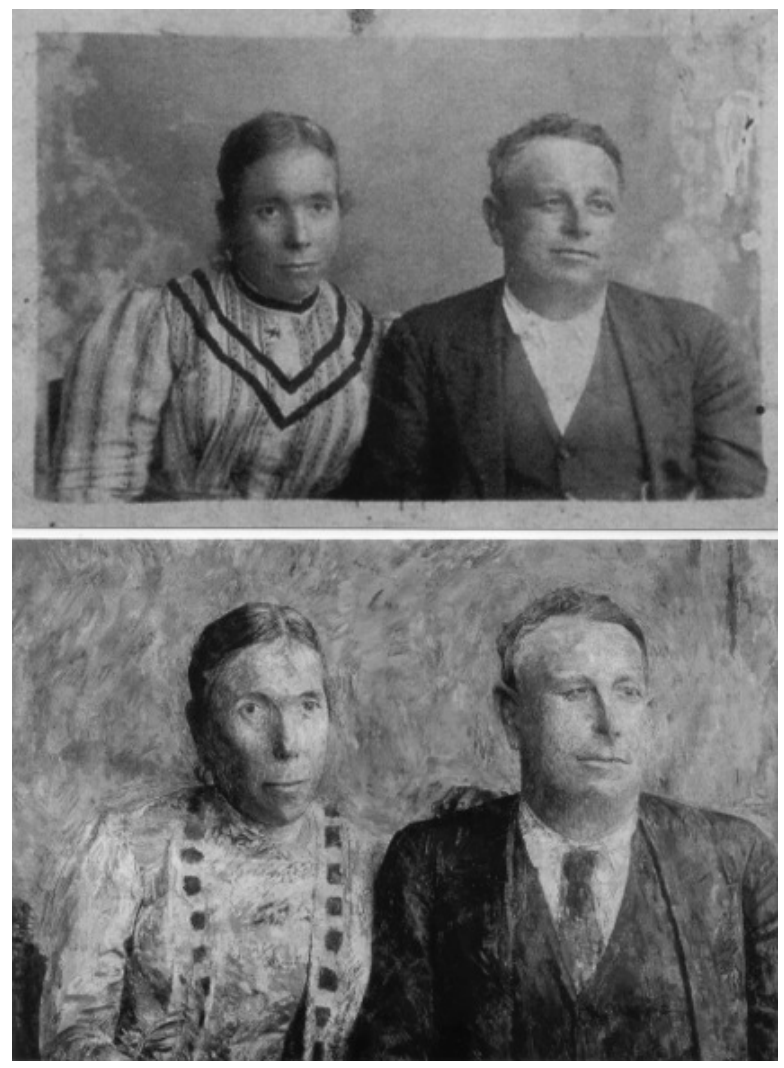

Figura 4. Fotografía y pintura de Josefa y Sinforoso (1955), abuelos maternos de Antonio López.

Con esos intereses, las pinceladas, extrañas a la fotografía, y como expresiones propias del oficio del pintor a través de la facilidad de ejecución y el dominio de la mano, se convertirían en algo neutralizado y denostado por él. Así, en unas declaraciones de 1997 afirmaba que "Eso que está de moda, lo de hacer mano, me parece una banalidad absoluta, la cosa más tonta del mundo. Es algo que me irrita muchísimo; si hablo mal de alguna cosa es precisamente de eso" (Gómez, 1999: 519). En relación con estas palabras, Juan José Gómez Molina, comentaba su conversación con Antonio López en donde declaraba estas opiniones, advertiendo certeramente que "Su trabajo es siempre un esfuerzo desmesurado por negar la presencia de las imágenes de la pintura en sus representaciones..." (Gómez, 1999: 519). En ese dilema la fotografía podía ser la alternativa a la renuncia de la pintura como referencia, ya que era imposible carecer absolutamente de cualquier antecedente, algo muy bien expresado en una máxima de Wölfflin cuando afirmaba que "todo cuadro debe más a otros cuadros que a la observación directa [del natural]" (Gombrich, 1979: 274), una afirmación que se puede generalizar diciendo que todo cuadro debe más a otras imágenes, entre las que, además de las pinturas, se pueden encontrar las fotografías. 
Refiriéndose a los primeros años de formación recordaba su pintura de 1954, Mujeres mirando los aviones, indicando que "todo procede de lo visto o entrevisto en fotografías en blanco y negro [...] Yo tuve, en el caballete donde yo pintaba [...] una tarjeta postal que me trajo Lucio Muñoz [...] Esta tarjeta postal copiaba un trozo, un fragmento de un mural de Arezzo" (López, 2007: 52). Del mismo modo, de su pintura Los novios, de 1955, precisa que "la cabeza es de un futbolista, de un cromo de un futbolista", para el que más tarde, en sus palabras, "cogí una fotografía de la boda de mi madre" (López, 2007: 55).

Es evidente que la fotografía, además de reproducir otras pinturas, ha logrado asumir casi desde el mismo momento de su invención el papel de ser el modelo más próximo a lo real, y de este modo cualquier pintura realista realizada actualmente del natural no puede evitar su dependencia de lo fotográfico, de uno u otro modo. Ante muchas obras actuales, realistas, pintadas del natural, como en la obra reciente de Antonio López, el público suele afirmar admirado que parecen fotografías, algo impensable al referirse a la obra de Caravaggio, Rembrandt o Velázquez, aunque su realismo sea evidente.

Recientemente, el mismo pintor, al ser preguntado por la influencia de la fotografía afirmaba que, "La fotografía y el cine, lo creas o no, nos ha influido a todos de una forma enorme. Cómo no te va a influir. La fotografía ha influido en la pintura desde que nació. A veces mal, pero al final bien. Yo pienso que somos de la misma familia” (Belzunze, F., Antonio López, pintor; «No nos aceptamos». Recuperado de: http://www.diariosur.es/v/20110626/cultura/antonio-lopez-pintoraceptamos-20110626.html).

Declaraba esta idea tras referirse a las dificultades del retrato de la Familia Real, comenzado en 1993, y respecto al cual confesaba: "el esquema que podía valerme [para el retrato] no existe en la pintura, yo creo. Es de nuestra época. Puede existir en la fotografía, incluso. O en el cine" (En el mismo lugar.). También recordaba el retrato de sus abuelos, pintado de una fotografía, "Ahora, cuando estoy haciendo el cuadro de los Reyes, que he vuelto a la fotografía, pienso mucho en estos cuadros" (López, 2007: 50).

Es bien sabido que para pintar a la Familia Real viene utilizado unas fotografías que se han publicado en varias ocasiones; en su propia descripción precisa que el cuadro, "no parte de una sola foto, sino de varias: es un collage. Rescaté unos detalles de aquí y otros de allí" ( "La verdadera historia del cuadro más esperado", XL Semanal, № 1.105, 2008, p. 24.).

Del mismo modo, en sus esculturas se ayuda de la fotografía, tal como se ve en muchas imágenes recientes trabajando en las cabezas de sus cuatro nietos con la ayuda de ampliaciones. Sobre ello hablaba de "la necesidad de realismo que puede tener el escultor. Lo ha puesto, lo coge de la fotografía" (López, 2007: 41). Para la escultura de los Reyes en el claustro de San Benito de Valladolid, realizada con los escultores Francisco López y Julio López, se planteó, en un principio, la posibilidad de "partir de una fotografía que yo había desechado de un encargo de la Familia Real [y cuando se decidió su realización] hubo que hacer más fotografías rodeando al grupo. Entonces nos citaron en la Zarzuela [...] y fuimos allí con los fotógrafos" (López, 2007: 41). 


\section{5. ¿Copiar fotografías?}

La deuda de la pintura de Antonio López hacia la fotografía es bien explícita en buena parte de su primera obra. Así, del retrato de Ataúlfo Argenta pintado en 1958 recordaba: "los periódicos dedicaron tras su prematura desaparición grandes espacios ilustrados por numerosas fotografías, la mayor parte de ellas sin una excesiva calidad, en blanco y negro, claro. Una de ellas me sirvió para hacer el cuadro. Para pintar sus manos, actuó de modelo, mostrándome las suyas, otro pintor de Santander, Enrique Gran, y la guitarra que aparece tras las partituras la tenía mi padre en su casa de Tomelloso" (Fig. 5) (Delgado, Jesús, "Antonio López cree "desmesurado" lo pagado por el retrato de Argenta", El País, 31-I-1989).
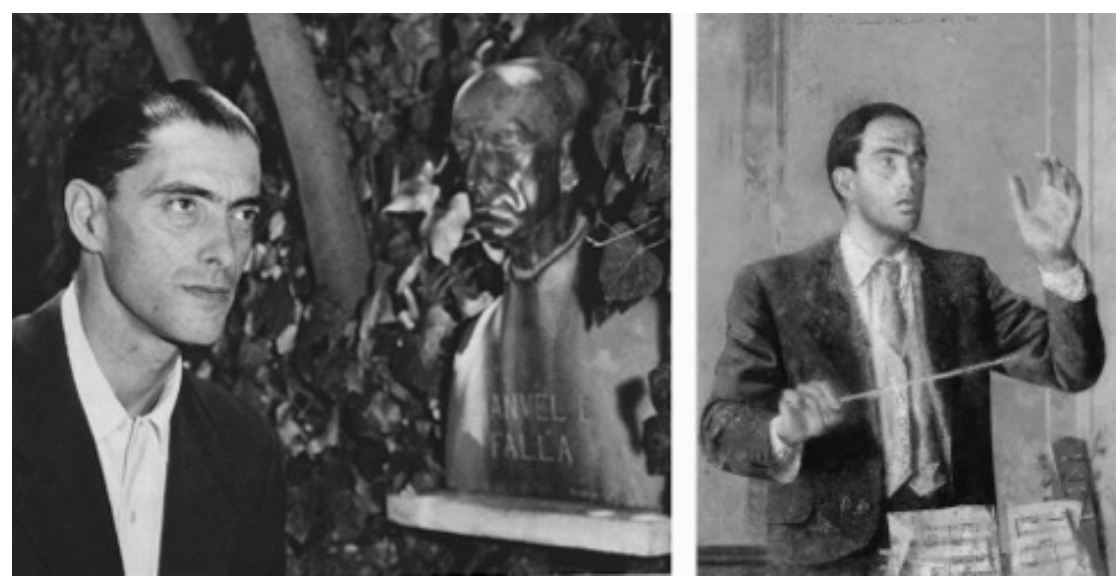

Figura 5. Ataulfo Argenta. Fotografía de un diario de la época y retrato de A. López realizado en 1958 tras su fallecimiento (Diputación Regional de Cantabria).

Remontándonos a las primeras etapas de su formación, y en relación directa con la fotografía "en blanco y negro, claro", el pintor ha recordado en muchas ocasiones los grabados procedentes de fotografías que copiaba de niño de La Ilustración Española y Americana, vistos por él como unas representaciones más reales que la gran pintura española del Siglo de oro. Al dibujar del natural, a los trece años, a instancias de su tío, refiere que le "decepcionaba algo el resultado de lo que iba saliendo, me parecía pobre comparado con las copias de las láminas de las pinturas del siglo XIX que había hecho hacía poco" (López, 2010:12). La anécdota de su primera visita al Museo del Prado con su tío pintor y su padre refiere su desilusión ante la pintura de Velázquez que le proponían como modelo de realismo, cuando para él, el modelo más convincente de la realidad estaba representado por los grabados de La Ilustración o la pintura de su propio tío. Paradójicamente, en los últimos años Antonio López viene afirmando insistentemente una opinión bien diferente al decir que en el arte no existe nada igual a la pintura de Velázquez "como representación del mundo real" (Informe Semanal, Antonio López, cara a cara con Velázquez en el Museo del Prado. 
Recuperado de: http://www.rtve.es/alacarta/videos/especial-antonio-lopez/antoniolopez-retratos-prado1/1127886/).

De la evolución de su criterio, en el discurso de la recepción del premio Velázquez 2006, volvía a recordar la conversación con su tío, pintor realista, tras visitar la pintura de Velázquez en el Museo del Prado: "al salir le confesé que me gustaba más su pintura [...] En realidad me costó largo tiempo ir comprendiendo el lenguaje, el enigma de la pintura" (Navarro, F.: Premio Velázquez 2006.Recuperado de: https://www.google. es/\#q=https:\%2F\%2Fwww.antoniolopezgarcia.blogspot.com\%2F2007\%2F05\% 2Fpremio-velazquez-2006.html\%E2\%80\%8E).

En sus reflexiones sobre Velázquez Antonio López pone su atención en la manera de hacer, más que en los temas elegidos por el pintor sevillano. Los cambios de criterio han sido grandes y reconocidos por él, como la valoración muy positiva de la pintura de Sorolla, algo absolutamente impensable en los años sesenta. En el año 2009 recordaba de sus primeras etapas: "cuando me formé en los cincuenta, Sorolla y lo sorollesco no podía estar más desacreditado". Se podría asegurar que en los años sesenta, cuando era profesor en Bellas Artes habría censurado cualquier intento de emulación de la pintura de Sorolla. Cuarenta años más tarde diría: "Sorolla y la pintura es casi la misma cosa", destacando "su capacidad innata de pintar" (Informe Semanal RTVE 1, 4 de junio, 2009.). Asimismo, comentando en el año 2007 una pintura suya de 1960 diría que ahora "lo hubiera pintado como lo hubiera hecho Sorolla. Es decir, tal y como lo veía" (López, 2007: 58).

Aunque ha sido muy grande la evolución de su criterio, ha sido mayor la evolución de la fotografía desde la España de finales de los cincuenta hasta el cambio de siglo. Sólo basta comparar fotografías de diferentes épocas relacionadas con sus pinturas, como la de sus abuelos, frente a las de la Familia Real utilizadas para pintar el retrato.

Ciertamente, al comparar las fotografías más antiguas, se puede recordar la idea de la pérdida del aura proclamada por Walter Benjamin. La fotografía de los abuelos de Antonio López, Josefa y Sinforoso, evoca una "lejanía" imposible de reconstruir con una imagen digital actual; el culto a los seres lejanos o difuntos en los retratos fotográficos antiguos es un último episodio de la existencia del "aura" definida por el filósofo alemán. También Antonio López confesaba su relación sentimental con las fotografías familiares, imposible respecto a las de personas desconocidas: "Y no recreaba aquellas fotografías de mis mayores por estética, sino por un instinto íntimo, que no puedo trasladar a las fotografías de otros seres a los que no estoy ligado" (García Pavón, 1977: 58, 59).

También la calidad de las actuales fotografías en color es muy superior a las de hace pocas décadas, algo que explica la existencia de fenómenos relativamente recientes, como el del fotorrealismo en la pintura, en donde muchos se limitan a copiar fotografías por el método de la cuadrícula o proyectándolas sobre el cuadro. No obstante, Antonio López hoy reivindica el acercamiento a la realidad desde la estrategia del pintor de caballete, a pesar de que algunas de sus obras están realizadas con la ayuda de fotografías, como en el caso del cuadro Madrid desde Capitán Haya del que confesaba: "yo sí que uso la fotografía, por ejemplo, en Capitán Haya, donde había una luz sumamente rápida. Ahí sí que cogí e hice una fotografía del momento. Entonces trabajaba con la fotografía cuando la luz se pasaba y hasta que la luz llegaba. 
Me ponía tan sumamente nervioso con un cuadro tan sumamente grande, que cuando me quería dar cuenta ya la luz estaba en otro lado. Tenía que esperar hasta el día siguiente. Entonces la fotografía me daba un poco el sitio de las sombras" (López, 2007: 83).

No obstante, han de matizarse las diferencias entre una concepción fotográfica de la representación visual y la copia sumisa y artesanal de una fotografía, cuadriculándola minuciosamente para reproducirla cuadrado a cuadrado, de forma similar al pixelado de las imágenes digitales. El uso de este método por Antonio López se ha dado a conocer recientemente con la publicación de algunos dibujos del proceso del retrato de la Familia Real, copiado de fotografías con la ayuda de la cuadrícula.

\section{Pintar del natural}

A pesar de las evidencias, estos métodos están obviados en la enseñanza actual. Así, preguntado en 2008 sobre el "primer consejo" dado a los que asistían a sus cursos de pintura decía sólo "sugerir", después de una reflexión, "ahora en la figuración se usa mucho la fotografía. Me parece una tontería [...] yo les sugiero que trabajen del natural". Sin embargo su rechazo a la ayuda de la fotografía no es total, al precisar que ese modo de trabajar, durante el curso sólo se "aparca" (Antonio López en TVE, 6 de junio de 2008.).

Poco tiempo después, en otra entrevista volvía a insistir sobre el mismo problema sin aportar en su respuesta argumentos convincentes de las diferencias conceptuales entre ambas:

"¿Definitivamente, el pintor figurativo no debe competir con la fotografía? Son mundos distintos, ni puede ni debe. Como se ponga a competir pierde. Es un espacio muy diferente, $[\ldots]$ La pintura está para dialogar con los demás, para dar tu punto de vista, estás obligado a darlo. Yo creo que el fotógrafo no debe dar su punto de vista, debe dar un testimonio, si hablamos de la guerra de España el fotógrafo no debe ponerse él, Goya se pone él, Picasso se pone él, ésa es la diferencia: el fotógrafo no debe ponerse, debe ser un testigo nada más, y en ese sentido, la máquina que tiene y le acompaña es el instrumento ideal" (Frechilla, K., Jiménez, A., Entrevista a Antonio López. Recuperado de: https://www.elecohernandiano.com+26+antonio+lopez).

En estas circunstancias, ha de advertirse que la fotografía no es algo intemporal al margen de los problemas de estilo; posiblemente hay tanta diferencia entre una fotografía de los años cincuenta y una fotografía digital actual, como la diferencia que existe entre un retrato de los tiempos de Giotto y otro de la época de Durero. A lo largo de las últimas décadas, tanto las fotografías como las pinturas vinculadas a ellas han cambiado drásticamente. En la obra de Antonio López existe una gran diferencia entre el cuadro de la Vista de Nueva York desde un avión, pintado en 1963 a partir, obviamente, de una fotografía (Fig. 6) -él no viajará a aquella ciudad hasta 1985, y las vistas actuales de ciudades ayudadas algunas veces por fotografías ante la imposibilidad material de realizarlas totalmente del natural. En una crónica reciente de la visita del pintor a Bilbao en 2011, recogida por muchos medios de comunicación, tras ser invitado a subir a la Torre Iberdrola de 165 metros de altura, confesaba: "Hace años que quiero pintar Bilbao, desde que vi una fotografía en la portada de 
un libro". De este modo él sitúa la fascinación por aquella imagen fotográfica en el origen de su deseo de pintar una vista de gran tamaño, para lo cual aprovechó la visita tomando personalmente sus propias fotografías.
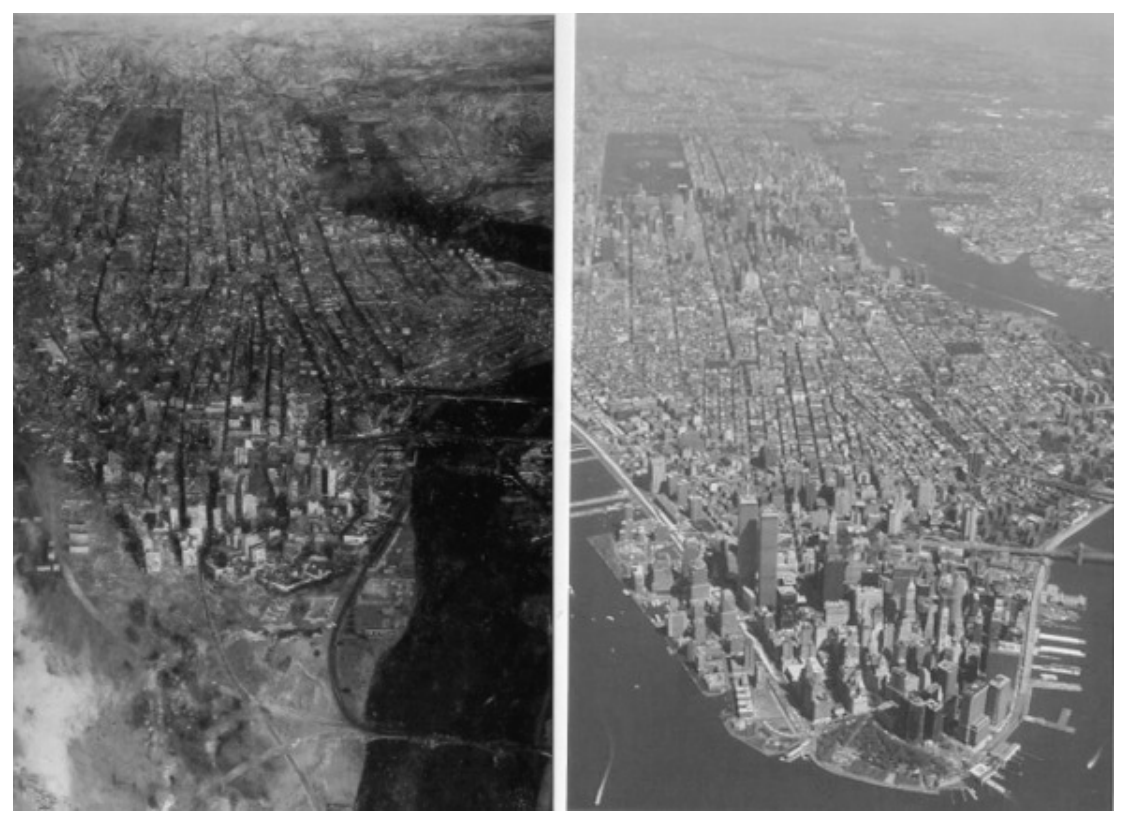

Figura 6. Vista de Nueva York (1963) y fotografía aérea actual.

En fechas aún más recientes, también ha declarado el deseo de pintar una vista de Sevilla "al natural, que es como mejor sale" aunque, por la propia dinámica del trabajo reconocía como algo inevitable, que se deberá "ayudar de fotografías" (diariodesevilla.es 30 de junio de 2012).

\section{Elección de modelos con "misterio"}

Volviendo a retomar su manera de enseñar en el año 1965, en la Escuela de San Fernando, se puede recordar que el único método admitido oficialmente para aprender a pintar era la copia directa del natural. La copia de láminas era inconcebible, y el uso de imágenes del arte moderno o la utilización de fotografías estaba proscrito. De los años de su propia formación el pintor recordaba que al encontrar en la biblioteca de Bellas Artes un libro sobre Picasso "sentías algo oscuro que te atraía y algo que temías" (Fernández-Braso, 1977: 13). En consecuencia, al tener que proponer modelos para enseñar a pintar, como profesor se valía de personalísimas naturalezas muertas montadas por él, con las que sorprendía a los alumnos, unas propuestas alejadas de la tradición de los géneros académicos estabilizados en el siglo XIX, y que sus alumnos nombraban como un nuevo género, "antoñitesco".

Sobre ello recordaba una anécdota: "Un día me cogió Eusebio Sempere y me puso 
verde, porque decía que estaba marcando una estética en la clase" (López, 2007: 28). La crítica era cierta y como testimonio de ello conocemos cuadros realizados por sus alumnos en aquel curso 1965-66, a partir de sus "bodegones", como una máquina de coser y una estufa (Fig 7 a,b). Además de pintar estos modelos, los alumnos buscaban en el aula sus propios motivos "antoñitescos", acordes con el fascinante imaginario del joven profesor. Como la pintura de una bombilla colgada del techo del aula, realizada por el pintor Pedro Cano cuando era alumno en aquel curso, y de quien Antonio López recuerda: "era muy joven y yo también, yo tenía treinta y él tendría veinte $[\ldots]$ de Pedro se notaba no sólo que era una persona con facilidad, sino con talento para pintar" (Frechilla, K., Jiménez, A., Entrevista a Antonio López. Recuperado de:_https://www.elecohernandiano.com+26+antonio+lopez).

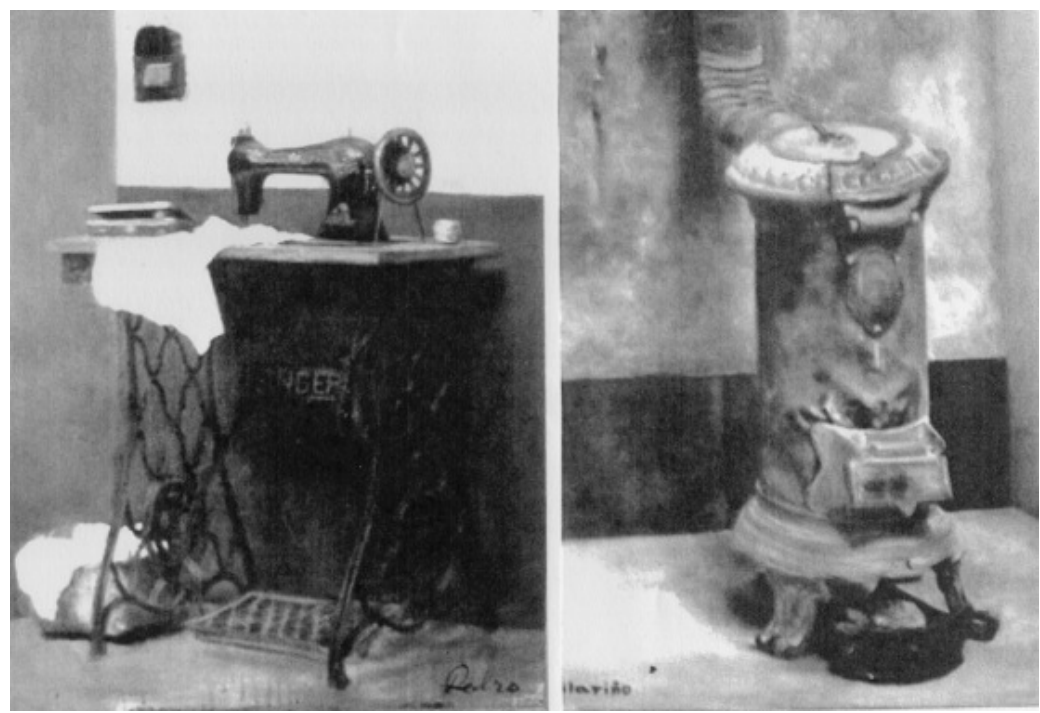

Figura 7. Máquina de coser y estufa, pinturas realizadas en 1966 en la Escuela de Bellas Artes a propuesta de Antonio López como profesor (P. Cano y J. Vilariño).

Al comentar el trabajo cotidiano de los estudiantes, Antoñito hacía continuas referencias al "misterio", tanto de los temas propuestos y situados ante la vista, así como de los efectos y resultados en los propios cuadros. En aquel tiempo él pintaba su Aparador, un tema similar al de las naturalezas muertas que proponía a sus alumnos. En uno de sus montajes en el aula, en donde se evocaba una especie de mesa de altar, incluyó una lamparilla de aceite, aunque las larguísimas jornadas impedían tenerla permanentemente encendida. La pretensión no era la de aprender a pintar la débil llama, sino de crear un clima de misterio en el modelo. No se puede olvidar que él mismo había utilizado este recurso surrealista de una llama en varios cuadros, como La madrugada (1958), Mari en Embajadores (1962) o La alacena (1963).

Para aumentar el efecto misterioso en una pintura, enseñaba a quemar de forma controlada su superficie, después de colocar la tabla sobre el suelo e impregnarla con alcohol y aguarrás. De este modo se lograba un efecto de deterioro similar al 
que produce el paso del tiempo, algo que evocan, muchas veces, las fotografías antiguas. Era una técnica utilizada en su pintura de aquellos años y que muchos de sus discípulos asumieron técnicamente al incorporar un soplete de fontanero entre sus instrumentos de trabajo, del mismo modo que el maestro. No obstante, el uso de este recurso desaparecería absolutamente en su obra posterior. En el año 2007 recordaba de aquellos años: "esta estética de la mancha por la mancha. Yo lo veo clarísimamente en una etapa de mi juventud, y a mí eso me parece una debilidad. Sí, es una debilidad. ¡Qué le vamos a hacer!" (López, 2007: 44).

La deuda de estos recursos no era sólo hacia la fotografía o el surrealismo, también era deudora del informalismo y la "pintura matérica", algo que se traducía en gruesos empastes, muchas veces quemados, manchados y con erosiones similares a obras informalistas como las de su gran amigo Lucio Muñoz, unas obras que venía realizando desde finales de los años cincuenta con maderas talladas, quemadas y enmohecidas. Se puede recordar que la obra personalísima de Lucio Muñoz adquirió gran notoriedad a partir de la que fue primera de las exposiciones individuales organizadas por la recientemente inaugurada Galería Juana Mordó de Madrid en el año 1964, en donde Lucio llegaría a realizar un total de seis. La admiración y la relación de la pintura de Antoñito con la obra de Lucio era evidente, como su amistad personal, y no sólo afectaba a su obra de entonces, también impregnaba la forma de enseñar a sus alumnos para el tratamiento del cuadro, como la sugerencia de preparar su superficie con los restos de la limpieza de las paletas. El éxito de la riqueza expresiva del tratamiento material de la superficie se conocía entonces como el dominio de las "calidades".

Las "calidades" de los chorreones de suciedad pintados en su cuadro Taza de váter $y$ ventana (1968-71), igual que en la Nevera de hielo, también muestran su interés por el envejecimiento y el deterioro de los materiales, aunque con el paso del tiempo desaparecería totalmente ese interés por la suciedad para dejar paso a la pulcritud de obras como la Nevera nueva de los años noventa. La fascinación por la "suciedad" ilustra su capacidad de dirigir la mirada, como un descubridor de otros mundos posibles, hacia temas ajenos a la rutina académica. Se ha escrito con gran acierto que la pintura de Antoñito de aquellos años, nos descubría "aquellas cosas que también vivían en la realidad" (en la nuestra y en la suya) y que la gente común no veíamos, no percibíamos, no sospechábamos siquiera la existencia de esos "elementos" que él nos mostraba y enfatizaba en sus obras. Cada obra de Antonio López era una revelación, una cierta epifanía" (EL OTRO, Antonio López "en bonito". Recuperado de:https:// www.escomberoides.blogspot.com/2011 06_01_archive.html).

Respecto a ello, el pintor Florencio Galindo, como antiguo alumno, recordaba de su experiencia en aquel curso 1965-66: "Antonio me hizo ver que el sujeto del arte ya era otra cosa. En su caso, un lavabo viejo. En el mío un perro metido en un cajón" (En El Semanal $N^{\circ} 678$ de octubre de 2000).

Es bien cierto que aquella técnica matérica de pintar con deterioros y envejecimiento de la superficie se remite a un mundo que no siempre se encuentra en la realidad, y en todo caso tiene más de imaginario que de real; un mundo que poco a poco irá desapareciendo de su obra para dejar paso a una forma de pintar más nítida y al servicio del puro dato visual, cada vez más alejada de los ecos surrealistas e informalistas de 
su primera obra. En el año 2007 él recordaba de la pintura de entonces: "yo noto que confiábamos muchísimo en el surrealismo. Era una coartada para aceptar la vida. A mí me costó muchísimo prescindir del surrealismo, lo reconozco, y cuando veo mis trabajos de cierta época creo que es una pena" (López, 2007: 38). En cuanto a la técnica material, indicaba de una obra: "llené de manchas, y lo llené de chorreones, y yo ahora lo siento muchísimo. Ahora lo haría más limpio" (López, 2007: 38).

De su actuación en aquella enseñanza académica que sólo concebía la copia del natural, se ha recordado que lo más insólito de su personalidad como profesor, además de su propia obra, eran, "los bodegones que ponía a sus alumnos en la Facultad de Bellas Artes [Escuela Superior], hechos con reliquias del rastro: alhacenas sombrías, vestiditos de niños al borde de la desintegración, neveras vacías, lavabos desconchados... Una orgía de "calidades" -puntillas, metales, lozas, brillos incontables- que creó escuela" (Gloria Otero, "Antonio López y el realismo. Mucho más que estilo". El Semanal, $N^{o} 678$, octubre de 2000, p. 28.).

Él mismo lo recordaba así: "Entonces cambié todos los modelos convencionales. Me llevé un montón de muebles, puse estufas, puse cunas, puse, iyo que sé!, puse toda esa cantidad de cosas para colocar, allí delante, en vez de unos objetos convencionales que no tenían sentido, una escena que reflejaba un poco el mundo" (López, 2007: 27).

La época del concurso-oposición, coincide con un cambio ya irreversible en su obra, para centrarse en la representación de objetos y figuras que también forman parte de su entorno afectivo inmediato, un cambio reconocido de forma unánime por la crítica. "El gusto por una representación de lo real en forma más directa y fiel ha sido determinante para Antonio López García a partir de los años sesenta" (Bonet, 1993: 20). El camino recorrido hasta llegar a definir su estilo de madurez fue algo difícil y reconocido por el mismo pintor al confesar: "descubrir el natural, y poder partir de él de una manera objetiva sin más, ha sido una conquista durísima" (López, 2007: 52). Curiosamente se trataba de un itinerario inverso al de su formación inicial "copiando la realidad [...] Es decir, copiar el modelo lo más fielmente posible" (López, 2007: 11).

\section{La maestría en la copia del natural}

Su paso como profesor de Bellas Artes le acercó más al sistema académico en donde el axioma fundamental imponía el deber de aprender a pintar copiando fielmente del natural los modelos propuestos por cada profesor. El discurso teórico en el aula necesariamente quedaba condicionado por la relación entre el dato visual y la pintura.

En el mismo concurso-oposición referido Antoñito pintó su Mujer desnuda sentada en una silla (Fig. 1b), se trataba de una "academia", nombre dado a una pintura o dibujo realizado del natural en una institución de enseñanza. En esta prueba lo importante era demostrar cómo se pintaba, ya que lo que se pintaba estaba impuesto por la propia institución, y en esa "academia" demostró su maestría. Todo el que haya tenido la oportunidad de ver directamente esta pintura convendrá en reconocer un dominio en el uso del color, un dominio que será clave para valorar su obra posterior.

Simultáneamente, la mirada y los temas pintados por Antonio López irían cambiando como el propio tiempo histórico, "desde la imagen ruralista de una España dominada por las más atávicas e inamovibles tradiciones, al Madrid que se despertaba 
lentamente del fantasma de la guerra y de la pobreza, y de ese conjunto de sórdidas imágenes a las más depuradas y límpidas de sus panorámicas y jardines de mediados de los años sesenta" (Viar, 2011: 63). Su pintura más reciente está relacionada con una nueva mirada de la ciudad, muy alejada del Tomelloso de su juventud o del Madrid de Atocha de su llegada a la capital. Al comentar en 2011 la vista de Bilbao desde la Torre Iberdrola hablaba satisfecho de una España "que se ha limpiado", añadiendo sorprendentemente que, a su entender, la capital vizcaína "ha pasado de ser un lugar decadente a una ciudad maravillosa. Algo parecido a la que ha sucedido en Valencia".

\section{Perspectiva geométrica y fotografía}

Volviendo al concurso-oposición que recordamos, el criterio académico exigía el dominio del oficio para copiar del natural y explica el argumento invocado para la reprobación de su Nevera de hielo. Cuando se expusieron públicamente las pinturas de Antoñito en la Escuela de Bellas Artes, se repetía y comentaba de boca en boca un argumento del tribunal para suspender al aspirante: estaba mal pintado porque "la puerta del congelador era mayor que la abertura correspondiente" i...? Si bien es cierta la impresión de que la puerta parece mayor, es algo tan absurdo como descalificar, por ejemplo, de la pintura de Cezanne por mayores "errores" de perspectiva. Como es bien patente, las pretendidas "razones" sólo eran una argumentación académica forzada, ante la imposibilidad de verbalizar las verdaderas razones en contra del pintor. Para ello se invocaban las supuestas leyes objetivas y universales de la perspectiva académica denunciando errores de medida.

El afán de desviar la atención hacia los problemas de perspectiva geométrica cerraba los ojos a una revolución de la imagen y de los modos de resolverla tras la aparición de la fotografía. Por ello. Desde la invención de la fotografía se ha venido advirtiendo de las aberraciones perspectivas respecto a las del sistema geométrico renacentista. Así, las supuestas distorsiones de las figuras de los primeros términos en las figuras de Degas se vienen explicando por su dependencia de la fotografía. En sintonía con una opinión muy generalizada, el pintor victoriano George Frederick Watts (1817-1904) llamó a las distorsiones perspectivas de la fotografía el "error moderno" que "ha introducido en el arte, desdichadamente, un error de perspectiva tan feo como falso" (Scharf, 1994: 202). Antonio López coincidía con estas opiniones afirmando: "quiero decir que hay una fotografía y la fotografía deforma. Yo lo sé por experiencia. Una fotografía deforma. La colocas así o asá, y se empiezan a mover las cosas" (López, 2007: 83).

Si admitiésemos que la reprobación de la Nevera de hielo de Antoñito se debió a su falta de dominio en el uso de la perspectiva geométrica, sería difícil de comprender el interés de algunos especialistas en el estudio del singular uso de la perspectiva en sus obras (Rabasa, 1995), del mismo modo que puede ser difícil de comprender el sentido de los sofisticados métodos de medición mostrados en la película $\mathrm{El} \mathrm{Sol} \mathrm{del}$ membrillo, en donde señala la posición de sus pies sobre el suelo con unos clavos, aunque se debe advertir que algunas escenas están reconstruidas para la película (Letras de cine, "Entrevista a Antonio López a propósito de El Sol del membrillo", octubre, 31,2008 .) y en cualquier caso es obvio que no se actúa igual en la soledad del estudio como al actuar ante la cámara con un guion o ante un gran número de 
espectadores, como se ha visto en los últimos años al pintar la Puerta del Sol con la ayuda de un visor y un compás, para medir los datos visuales después de señalar en el suelo las huellas de su calzado.

En cualquier caso, esos recursos técnicos no explican en absoluto la obra del pintor, aunque lamentablemente el gran público está dispuesto a creer que esas técnicas son el "secreto" esencial en el trabajo de creación de los pintores. En realidad, los métodos geométricos utilizados por el pintor son muy elementales, están recogidos en muchos manuales y son accesibles a cualquier estudiante, y en ningún caso son una clave para explicar su pintura.

La utilización de algunos recursos, como el trazado de unos ejes horizontal y vertical, o una cuadrícula, o un clavo para trazar con una cuerda tensada las fugas perspectivas de las estructuras arquitectónicas, son algo conocido desde siempre sin que puedan garantizar la perfección de sus resultados. La misma sencillez de su técnica se describe por el pintor: "ahora pongo un alfilerito muy fino en el sitio que es el punto de partida de donde arrancan todas las líneas de fuga. Es que todo esto es necesario, porque si no, ¿cómo narices te empiezas a ordenar todo ese mundo infinito de direcciones que son los puntos de fuga de tantos espacios arquitectónicos?". Más adelante añade: "Ya sé que la exactitud no te asegura nada, pero para mí es básica" (López, 2007: 44 y 83).

La reivindicación de la exactitud y la corrección "académica" de las fugas perspectivas en las estructuras llevó al pintor a modificar el cuadro Cabeza griega y vestido azul, intervenido 53 años después de su realización, cambiando la perspectiva de la contraventana al contradecir la apariencia de las casas de la calle (Fig. 8).

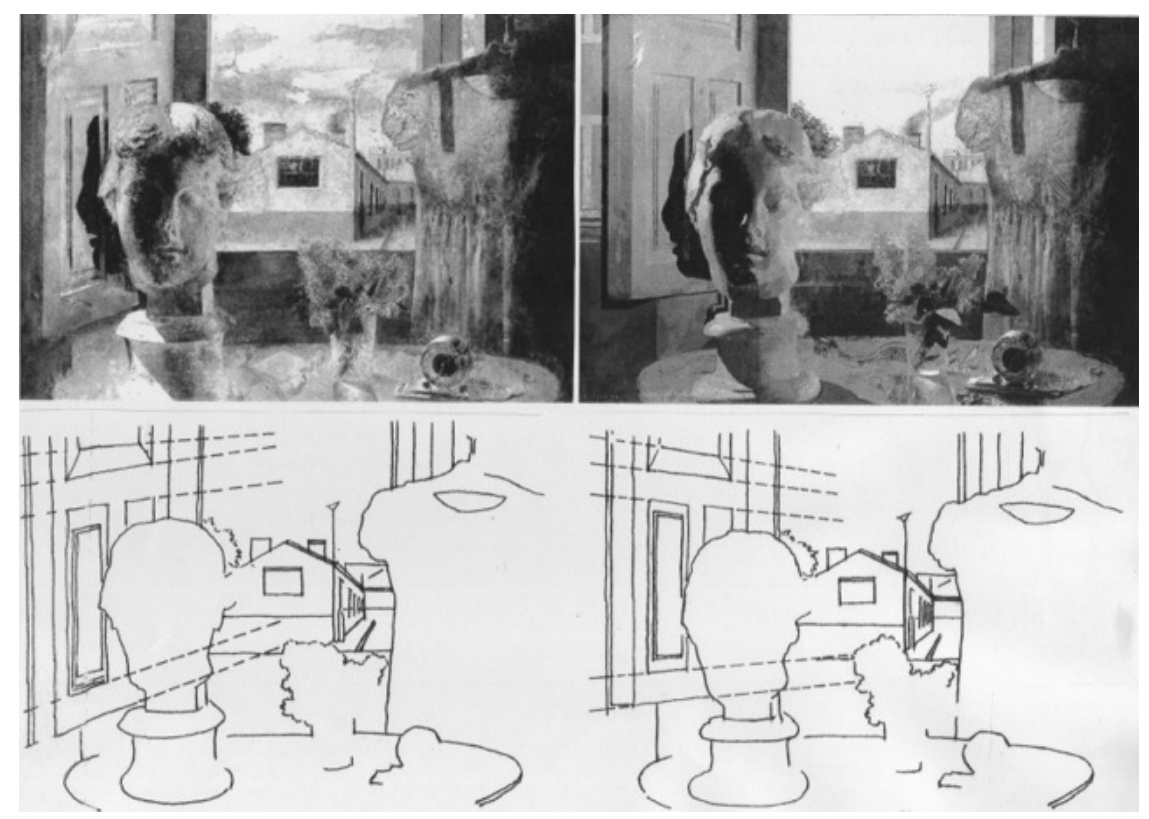

Figura 8. A. López. Cabeza griega y vestido azul (versión original de 1958 e intervención de 2011). Esquemas explicativos de la "corrección" de la perspectiva (L. Cabezas). 
Aunque se ha generalizado la idea de que la perspectiva geométrica es una técnica susceptible de una sistematización científica en tratados, es una concepción simplista, alejada de una historia de la pintura en donde para la representación del mundo visual no sólo se ha tenido en cuenta la perspectiva geométrica, también la perspectiva de los colores y la perspectiva atmosférica han tratado de establecer la continuidad entra los datos visuales y su representación gráfica.

En este sentido Antonio López hace una curiosa reflexión a propósito de los espacios de Las Meninas y Las hilanderas de Velázquez: "Yo no me creo la luz de esa habitación [...] Yo creo que en la pintura antigua, hasta el invento de la fotografía [...] pasa muchas veces eso. El primer pintor que intuyó la perspectiva moderna, o sea, la perspectiva visual tal y como nosotros vemos las cosas, es Vermeer. No es Velázquez" (López, 2007: 44 y 83).

Cuando se planteó dibujar la Casa de Antonio López Torres (1972-1975) en donde recuerda que "la habitación era pequeña $[. .$.$] me creaba tales problemas de$ perspectiva que, ya por fin, afronté, después de pensarlo mucho, la perspectiva curva. [...] En fin, empiezan a curvarse todos los elementos como en un ojo de pez y como lo ha resuelto, a veces, la fotografía. ¡El lenguaje de la fotografía!” (López, 2007: 80, 81) (Fig. 9).

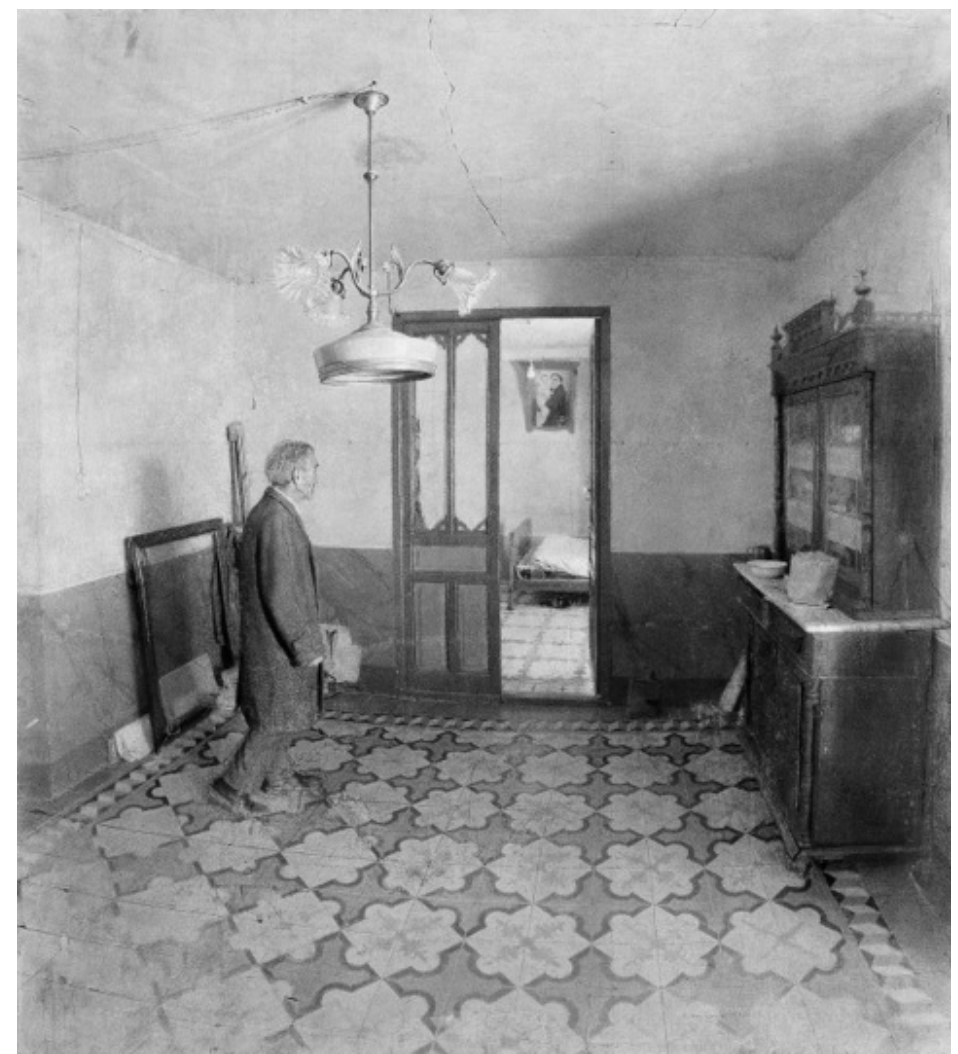

Figura 9. Casa de Antonio López Torres (1972-1975). 


\section{Conclusiones}

Más allá de las evidencias de la utilización de la fotografía como una herramienta presente en distintas fases de los procesos pictóricos del artista, el carácter fotográfico, cada vez más, influyó en la evolución de su obra. Lo fotográfico, poco a poco, con su autoridad como modelo de "lo real", explica el tránsito desde el primer "realismo mágico" de su juventud, con connotaciones e influencias surrealistas e informalistas, hasta la última obra en donde el dato visual, rotundamente objetivo, permite al pintor demostrar su magistral capacidad técnica para describir y expresar las impresiones visuales. El interés por la objetividad de la representación de su obra más reciente puede explicarse con ejemplos como la drástica corrección de la perspectiva "errónea" de una pintura de juventud, 53 años después de su realización, para adaptarla a unas leyes geométricas supuestamente más acordes con la "visión" fotográfica (Fig. 8).

\section{Referencias}

Bonet Correa, A. (1993). La leyenda de la realidad. Antonio López, pp. 29-38. Madrid: Museo Nacional Centro de Arte Reina Sofía.

Cabezas Gelabert, L. (2004). "El secreto de la representación objetiva: fabulación e investigación històrica; "El ojo ingenuo" y el conocimiento secreto de David Hockney". EGA, Expresión Gràfica Arquitectónica, no 9, pp. 38-49.

Fernández-Braso, M. (1977). Años de formación, Antonio López García. Cuadernos Guadalimar (2), pp. 3-30.

García Pavón, F. (1977). Segunda semblanza, Antonio López García. Cuadernos Guadalimar (2), pp. 58-59.

Gómez Molina, J. J. (1999). La estrategia del fracaso. Estrategias del dibujo en el arte contemporáneo, pp. 519-551. Madrid: Cátedra.

López, A. (2007). En torno a mi trabajo como pintor, pp. Valladolid: Fundación Jorge Guillén.

López, A. (2010). La Venus de Milo, Antonio López, Dibujos, pp.11-16. Madrid: T F Editores.

Scharf, A. (1994). Arte y fotografia. Madrid: Alianza Forma.

Rabasa Díaz, E. (1995). Los viejos problemas de la perspectiva en la pintura de Antonio López García. Academia, no 80, pp. 459-475.

Viar, J. (2001). Los lugares y el tiempo. (Tres cuestiones sobre Antonio López). Antonio López, pp. 63-97. Madrid: Museo Thyssen-Bornemisza. 
